\title{
Games Puzzle Hijaiyah Elektronik Interaktif Berbasis Mikrokontroler DT-AVR Maxiduino
}

\author{
Agus Mulyana ${ }^{1} \&$ Nasrudin $^{2}$ \\ ${ }^{1,2}$ Jurusan Sistem Komputer, Fakultas Teknik dan Ilmu komputer, UNIKOM Indonesia \\ Email: ${ }^{1}$ bagus081@gmail.com, ${ }^{2}$ dnazru18@gmail.com
}

\begin{abstract}
Abstrak. Puzzle hijaiyah Elektronik Interaktif adalah games edukasi kombinasi dari piranti lunak dan perangkat keras untuk membantu sarana pembelajaran anak-anak usia dini dalam pengenalan huruf-huruf hijaiyah Al-Quran. Pada saat penyusunan puzzle memiliki indikator berupa suara dan gambar animasi bergerak ketika penyusunan puzzle benar yang ditampilkan pada layar smartphone android. Pembuatan puzzle hijaiyah elektronik ini memanfaatkan alat-alat elektronik antara lain untuk membaca perubahan high atau low menggunakan sensor cahaya photodioda, untuk mengontrol menyala LED menggunakan IC demultiplexer, gerbang $O R$ digunakan untuk menggabungkan keluaran dari setiap sensor dan memanfaatkan keluaran logika low, mikrokontroler DT-AVR Maxiduino sebagai pengontrol kerja komponen lain dan pengolah data yang diterima dari setiap sensor, Basic4Android sebagai editor pembuatan interface pada smartphone android yang digunakan untuk mengolah data yang dikirim dari mikrokontroler, bluetooth HC-06 sebagai alat komunikasi antara mikrokontroler dengan smartphone android. Pengujian alat ini berfungsi $100 \%$ dalam pengiriman dan penerimaan data melalui komunikasi bluetooth, alat ini berhasil dan dapat digunakan. Diharapkan dengan adanya alat ini dapat membuat anak-anak lebih tertarik lagi untuk belajar sehingga untuk belajar Alquran dapat lebih menarik lagi dan dapat meningkatkan kemampuan berpikir dan membuat anak belajar berkonsentrasi.
\end{abstract}

Kata kunci: hijaiyah; game puzzle; mikrokontroler; DT-AVR Maxiduino.

\section{PENDAHULUAN}

Proses belajar huruf-huruf hijaiyah memiliki dua komponen penting yaitu pengajar dan anak-anak. Jika salah satu dari komponen ini tidak ada, maka proses belajar tidak akan berjalan. Proses belajar akan berjalan jika terjadi interaksi edukatif (kegiatan pembelajaran) antara pengajar dan para anak-anak. Dapat dikatakan suatu interaksi karena interaksi akan berlangsung bila ada hubungan timbal balik. Banyak faktor yang mempengaruhi keberhasilan dalam proses belajar mengajar. Faktor ini diantaranya adalah ketenangan, kesabaran dan ketertarikan anak-anak untuk belajar. 
Namun, seringkali pengajar belum mampu dalam menciptakan suasana pembelajaran yang mendukung faktor-faktor dalam mencapai keberhasilan belajar-mengajar tersebut. Sering ditemukan sebagian anak-anak mengalami titik kejenuhan dalam melaksanakan proses pembelajaran. Tentunya terdapat hal yang mendasar mengapa hal ini bisa terjadi dalam fenomena belajar kita selama ini. Oleh karena itu, dibutuhkan metode pengajaran yang dapat menciptakan suasana belajar yang berbeda dalam mendukung keberhasilan kegiatan belajar-mengajar tersebut yaitu membuat permainan yang dapat memicu daya tarik anak-anak untuk belajar (Edu Games).

\section{METODE}

\subsection{Perancangan Mekanik}

Perancangan mekanik untuk puzzle hijaiyah elektronik interaktif secara menyeluruh seperti terlihat pada Gambar 1.

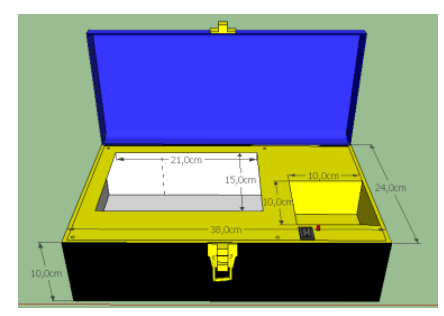

Gambar 1 Perancangan Box.

Puzzle dirancang sesuai dengan puzzle yang beredar di masyarakat luas, yaitu 30 keping sesuai jumlah huruf-huruf hijaiyah pada Al-Quran, untuk lebih jelas lagi dapat dilihat pada Gambar 2.

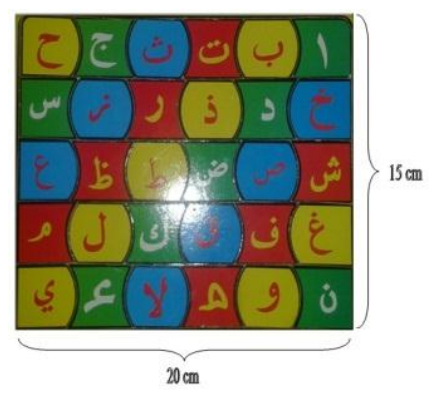

Gambar 2 Perancangan Papan Puzzle. 


\subsection{Perancangan Perangkat Keras}

Untuk Perancangan perangkat keras mempunyai diagram blok perancangan sistem yang dapat dilihat pada Gambar 3 dan Flowchart Sistem Puzzle Hijaiyah dapat dilihat pada Gambar 4.

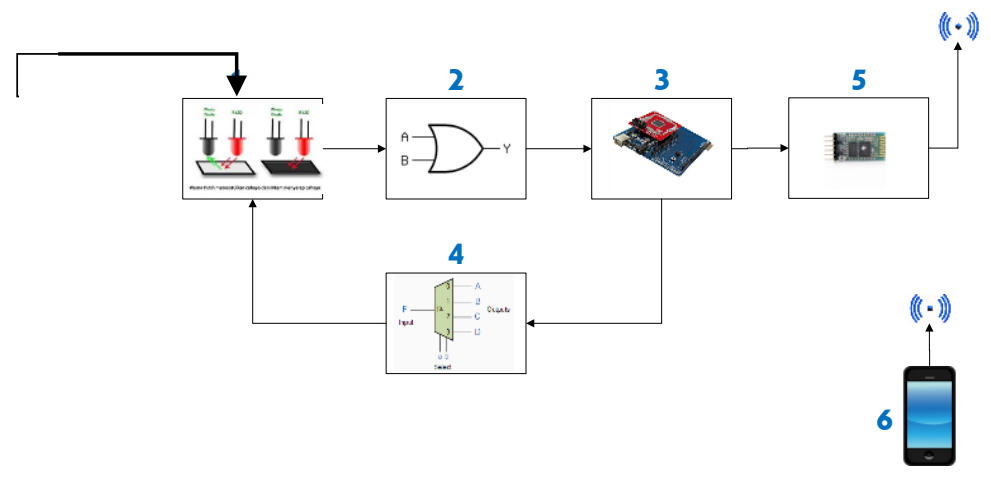

Gambar 3 Diagram blok perancangan sistem.

1) Sensor cahaya akan menghasilkan keluaran berupa tegangan, besarnya tegangan tergantung intensitas cahaya yang mengenai sensor.

2) Blok gerbang $O R$ berfungsi untuk menggabungkan beberapa output menjadi satu dan memanfaatkan kondisi logika low.

3) Blok mikrokontroler berfungsi sebagai kontrol unit yang akan menentukan keluaran pada layar smartphone.

4) Blok demultiplexer berfungsi sebagai selektor pemilih $L E D$ mana yang akan menyala.

5) Blok bluetooth berfungsi sebagai alat komunikasi antara mikrokontroler dan smartphone.

6) Blok smartphone berfungsi sebagai visualisasi dari permainan. 


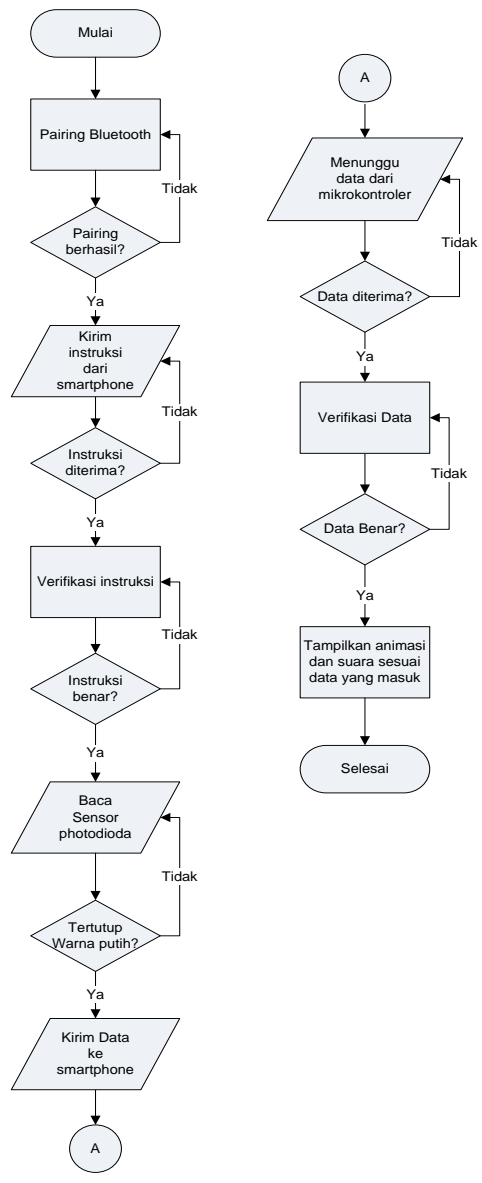

Gambar 4 Flowchart sistem puzzle hijaiyah.

\subsection{PENGUJIAN SISTEM}

Pengujian dilakukan dengan mengukur keluaran dari tiap sensor, apakah keluaran dari sensor berlogika $H I G H$ atau $L O W$ yang akan memutuskan tampilan gambar animasi dan suara pada layar smartphone seperti pada Tabel 1 .

Tabel 1 Tabel Nilai Logika Keluaran Sensor.

\begin{tabular}{cc}
\hline HIGH & LOW \\
\hline$>2$ Volt & $\leq 2$ Volt \\
\hline
\end{tabular}


Adapun hasil pengujian sensor dalam satuan Volt pada saat keadaan tertutup warna hitam dan putih. Hasil pengujian sensor warna dapat dilihat pada Tabel 2 sedangkan hasil presentase pengujian puzzle dapat dilihat pada Tabel 3.

Tabel 2 Pengujian sensor warna.

\begin{tabular}{|c|c|c|c|c|c|c|c|}
\hline \multirow{3}{*}{ No } & \multirow{3}{*}{ Puzzle } & \multicolumn{6}{|c|}{ Hasil Pengujian } \\
\hline & & \multirow{2}{*}{$\begin{array}{c}\text { Hitam } \\
(\mathbf{V})\end{array}$} & \multicolumn{2}{|c|}{ Gate OR } & \multirow{2}{*}{$\begin{array}{c}\text { Putih } \\
\text { (V) }\end{array}$} & \multicolumn{2}{|c|}{ Gate OR } \\
\hline & & & IN (V) & $\begin{array}{c}\text { OUT } \\
(\mathbf{V})\end{array}$ & & IN (V) & $\begin{array}{c}\text { OUT } \\
(\mathrm{V})\end{array}$ \\
\hline $\mathbf{1}$ & Alif & 4,11 & Tidak & Tidak & 0,332 & Tidak & Tidak \\
\hline 2 & $\mathrm{Ba}$ & 4,39 & Tidak & Tidak & 1,739 & Tidak & Tidak \\
\hline 3 & $\mathrm{Ta}$ & 3,28 & Tidak & Tidak & 0,164 & Tidak & Tidak \\
\hline 4 & \multirow{2}{*}{ Tsa } & 3,12 & 3,12 & 4,5 & 0,198 & 0,198 & 0,16 \\
\hline 5 & & 4,15 & 4,15 & & 0,437 & 0,437 & \\
\hline 6 & \multirow{2}{*}{ Dzim } & 3,5 & 3,5 & 4,64 & 0,185 & 0,185 & 0,157 \\
\hline 7 & & 3,88 & 3,88 & & 0,212 & 0,212 & \\
\hline 8 & \multirow{2}{*}{$\mathrm{Ha}$} & 3,78 & 3,78 & 4,81 & 0,186 & 0,186 & 0,165 \\
\hline 9 & & 3,58 & 3,58 & & 0,173 & 0,173 & \\
\hline 10 & Kho & 4,59 & Tidak & Tidak & 1,89 & Tidak & Tidak \\
\hline 11 & Dzal & 3,63 & Tidak & Tidak & 0,175 & Tidak & Tidak \\
\hline 12 & \multirow{4}{*}{ Dza } & 3,56 & 3,56 & 4,36 & 0,262 & 0,262 & 0,164 \\
\hline 13 & & 4,19 & 4,19 & & 0,991 & 0,991 & \\
\hline 14 & & 3,15 & 3,15 & & 0,156 & 0,156 & \\
\hline 15 & & 3,41 & 3,41 & & 0,18 & 0,18 & \\
\hline 16 & \multirow{3}{*}{ Rho } & 2,65 & 2,65 & 4,53 & 0,142 & 0,142 & 0,167 \\
\hline 17 & & 4,02 & 4,02 & & 0,181 & 0,181 & \\
\hline 18 & & 3,93 & 3,93 & & 0,223 & 0,223 & \\
\hline 19 & \multirow{3}{*}{ Dzai } & 3,69 & 3,69 & 4,53 & 0,155 & 0,155 & 0,155 \\
\hline 20 & & 4,55 & 4,55 & & 1,14 & 1,14 & \\
\hline 21 & & 2,54 & 2,54 & & 0,114 & 0,114 & \\
\hline 22 & \multirow{2}{*}{$\operatorname{Sin}$} & 2,88 & 2,88 & 4,51 & 0,126 & 0,126 & 0,17 \\
\hline 23 & & 4,46 & 4,46 & & 0,213 & 0,213 & \\
\hline 24 & Syin & 4,56 & Tidak & Tidak & 0,195 & Tidak & Tidak \\
\hline 25 & Syod & 4,64 & Tidak & Tidak & 1,28 & Tidak & Tidak \\
\hline 26 & \multirow{2}{*}{ Dod } & 3,12 & 3,12 & 4,39 & 0,137 & 0,137 & 0,166 \\
\hline 27 & & 3,48 & 3,48 & & 0,157 & 0,157 & \\
\hline 28 & \multirow{2}{*}{ Tho } & 3,61 & 3,61 & 4,49 & 0,141 & 0,141 & 0,161 \\
\hline 29 & & 4,27 & 4,27 & & 0,243 & 0,243 & \\
\hline 30 & \multirow{2}{*}{ Dzo } & 3,62 & 3,62 & 4,68 & 0,143 & 0,143 & 0,168 \\
\hline 31 & & 3,87 & 3,87 & & 0,176 & 0,176 & \\
\hline 32 & Ain & 2,83 & 2,83 & 4,31 & 0,165 & 0,165 & 0,178 \\
\hline
\end{tabular}




\begin{tabular}{|c|c|c|c|c|c|c|c|}
\hline \multirow{3}{*}{ No } & \multirow{3}{*}{ Puzzle } & \multicolumn{6}{|c|}{ Hasil Pengujian } \\
\hline & & \multirow{2}{*}{$\begin{array}{c}\text { Hitam } \\
(\mathbf{V})\end{array}$} & \multicolumn{2}{|c|}{ Gate OR } & \multirow{2}{*}{$\begin{array}{c}\text { Putih } \\
\text { (V) }\end{array}$} & \multicolumn{2}{|c|}{ Gate OR } \\
\hline & & & IN (V) & $\begin{array}{c}\text { OUT } \\
(\mathbf{V})\end{array}$ & & IN (V) & $\begin{array}{c}\text { OUT } \\
(\mathrm{V})\end{array}$ \\
\hline 33 & & 4,41 & 4,41 & & 0,801 & 0,801 & \\
\hline 34 & & 2,64 & 2,64 & & 0,168 & 0,168 & \\
\hline 35 & Ghin & 3,18 & Tidak & Tidak & 0,13 & Tidak & Tidak \\
\hline 36 & $\mathrm{Fa}$ & 4,12 & Tidak & Tidak & 0,169 & Tidak & Tidak \\
\hline 37 & Kof & 4,16 & Tidak & Tidak & 0,18 & Tidak & Tidak \\
\hline 38 & & 4,41 & 4,41 & 4,33 & 0,226 & 0,226 & 0,173 \\
\hline 39 & & 3,88 & 3,88 & & 0,188 & 0,188 & \\
\hline 40 & Kaf & 4,14 & 4,14 & & 0,192 & 0,192 & \\
\hline 41 & & 3,88 & 3,88 & & 0,162 & 0,162 & \\
\hline 42 & & 4,43 & 4,43 & 4,38 & 0,61 & 0,61 & 0,169 \\
\hline 43 & Lam & 3 & 3 & & 0,155 & 0,155 & \\
\hline 44 & & 4 & 4 & & 0,186 & 0,186 & \\
\hline 45 & & 4,05 & 4,05 & 4,37 & 0,165 & 0,165 & 0,173 \\
\hline 46 & Mim & 4,12 & 4,12 & & 0,182 & 0,182 & \\
\hline 47 & & 3,11 & 3,11 & & 0,137 & 0,137 & \\
\hline 48 & & 3,51 & 3,51 & 4,72 & 0,169 & 0,169 & 0,155 \\
\hline 49 & Nun & 3,52 & 3,52 & & 0,164 & 0,164 & \\
\hline 50 & Wau & 4,39 & Tidak & Tidak & 0,299 & Tidak & Tidak \\
\hline 51 & & 3,9 & 3,34 & 4,34 & 0,135 & 0,135 & 0,152 \\
\hline 52 & Kha & 3,29 & 4,04 & & 0,155 & 0,155 & \\
\hline 53 & & 3,68 & 3,61 & 4,61 & 0,148 & 0,148 & 0,173 \\
\hline 54 & Lam'Alif & 4,5 & 4,71 & & 1,11 & 1,11 & \\
\hline 55 & & 3,9 & 4,31 & 4,41 & 0,168 & 0,168 & 0,177 \\
\hline 56 & Hamzah & 3,91 & 4,27 & & 0,169 & 0,169 & \\
\hline 57 & & 3,84 & 4,5 & & 0,158 & 0,158 & \\
\hline 58 & & 3,98 & 4,62 & 3,86 & 0,173 & 0,173 & 0,685 \\
\hline 59 & Iya & 4,22 & 4,56 & & 0,443 & 0,443 & \\
\hline 60 & & 2,88 & 3,72 & & 0,143 & 0,143 & \\
\hline
\end{tabular}


Tabel 3 Persentase pengujian puzzle.

\begin{tabular}{|c|c|c|c|c|c|}
\hline \multirow[b]{2}{*}{ No. } & \multirow[b]{2}{*}{ Puzzle } & \multicolumn{2}{|c|}{ Bluetooth } & \multirow{2}{*}{$\begin{array}{l}\text { Verifikasi } \\
\text { Data }\end{array}$} & \multirow{2}{*}{$\begin{array}{l}\text { Keber- } \\
\text { hasilan }\end{array}$} \\
\hline & & $\begin{array}{c}\text { Kirim } \\
\text { Data }\end{array}$ & $\begin{array}{c}\text { Terima } \\
\text { Data }\end{array}$ & & \\
\hline 1. & & Alif & Alif & Benar & Berhasil \\
\hline 2. & & $\mathrm{Ba}$ & $\mathrm{Ba}$ & Benar & Berhasil \\
\hline 3. & & $\mathrm{Ta}$ & $\mathrm{Ta}$ & Benar & Berhasil \\
\hline 4. & & Tsa & Tsa & Benar & Berhasil \\
\hline 5. & & Dzim & Dzim & Benar & Berhasil \\
\hline 6. & & $\mathrm{Ha}$ & $\mathrm{Ha}$ & Benar & Berhasil \\
\hline 7. & & Kho & Kho & Benar & Berhasil \\
\hline 8. & & Dzal & Dzal & Benar & Berhasil \\
\hline 9. & & Dza & Dza & Benar & Berhasil \\
\hline 10. & & Rho & Rho & Benar & Berhasil \\
\hline 11. & & Dzai & Dzai & Benar & Berhasil \\
\hline 12. & & Sin & Sin & Benar & Berhasil \\
\hline 13. & & Syin & Syin & Benar & Berhasil \\
\hline 14, & & Syod & Syod & Benar & Berhasil \\
\hline 15. & & Dod & Dod & Benar & Berhasil \\
\hline 16. & & Tho & Tho & Benar & Berhasil \\
\hline 17. & & Dzo & Dzo & Benar & Berhasil \\
\hline 18. & & Ain & Ain & Benar & Berhasil \\
\hline
\end{tabular}




\begin{tabular}{|c|c|c|c|c|c|}
\hline \multirow[b]{2}{*}{ No. } & \multirow[b]{2}{*}{ Puzzle } & \multicolumn{2}{|c|}{ Bluetooth } & \multirow{2}{*}{$\begin{array}{l}\text { Verifikasi } \\
\text { Data }\end{array}$} & \multirow{2}{*}{$\begin{array}{l}\text { Keber- } \\
\text { hasilan }\end{array}$} \\
\hline & & $\begin{array}{l}\text { Kirim } \\
\text { Data }\end{array}$ & $\begin{array}{c}\text { Terima } \\
\text { Data }\end{array}$ & & \\
\hline 19. & & Ghin & Ghin & Benar & Berhasil \\
\hline 20. & & $\mathrm{Fa}$ & $\mathrm{Fa}$ & Benar & Berhasil \\
\hline 21. & & Kof & Kof & Benar & Berhasil \\
\hline 22. & & Kaf & Kaf & Benar & Berhasil \\
\hline 23. & & Lam & Lam & Benar & Berhasil \\
\hline 24. & & Mim & Mim & Benar & Berhasil \\
\hline 25. & & Nun & Nun & Benar & Berhasil \\
\hline 26. & & Wau & Wau & Benar & Berhasil \\
\hline 27. & & Kha & Kha & Benar & Berhasil \\
\hline 28. & & Lam'Al & Lam'Alif & Benar & Berhasil \\
\hline 29. & & Hamzah & Hamzah & Benar & Berhasil \\
\hline 30. & & Iya & Iya & Benar & Berhasil \\
\hline
\end{tabular}

Persentase keberhasilan untuk pengiriman dan penerimaan data melalui komunikasi bluetooth.

$$
\begin{aligned}
\% \text { Keberhasilan } & =\frac{\text { Jumlah Verifikasi data yang benar }}{\text { Jumlah kepingan puzzle }} \times 100 \% \\
& =\frac{30}{30} \times 100 \% \\
& =100 \%
\end{aligned}
$$




\section{HASIL DAN PEMBAHASAN}

\subsection{Perangkat}

\section{a. Photodioda}

Photodioda adalah suatu jenis dioda yang bekerja berdasarkan intensitas cahaya, dimana jika terkena cahaya maka bekerja seperti dioda pada umumnya, tetapi jika tidak mendapat cahaya maka akan berperan seperti resistor dengan nilai tahanan yang besar sehingga arus listrik tidak dapat mengalir. Simbol dan bentuk Photodioda dapat dilihat pada Gambar 5.

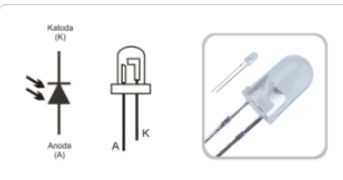

Gambar 5 Simbol dan bentuk photodioda.

\section{b. LED (Light Emitting Diode)}

Light Emitting Diode (LED) adalah perangkat semikonduktor yang menghasilkan cahaya ketika arus listrik melewati celah antara katoda dan anoda didalam sistem perangkat tersebut. Warna yang dihasilkan bergantung pada bahan semikonduktor yang dipakai. Simbol dan bentuk LED dapat dilihat pada Gambar 6.

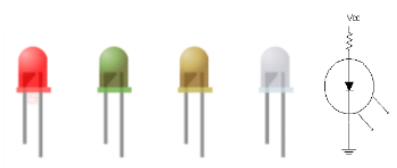

Gambar 6 Bentuk dan simbol LED.

\section{c. Demultiplexer}

Demultiplexer adalah perangkat elektronik yang berfungsi untuk memilih salah satu data dari banyak data menggunakan suatu data input. Pada Gambar 7 menunjukkan Simbol Demultiplexer 2 ke-4.

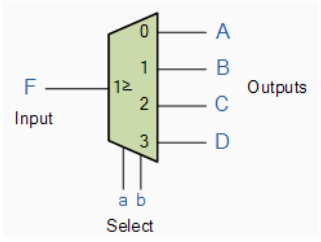

Gambar 7 Simbol demultiplexer 2 ke-4. 


\subsection{Gerbang OR}

Gerbang $O R$ mempunyai dua atau lebih dari dua sinyal masukan tetapi hanya satu sinyal keluaran. Gerbang $O R$ akan memberikan sinyal keluaran tinggi jika salah satu atau semua sinyal masukan bernilai tinggi, sehingga dapat dikatakan bahwa gerbang $O R$ hanya memiliki sinyal keluaran rendah jika semua sinyal masukan bernilai rendah. Untuk simbol Gerbang $O R$ masukan dapat dilihat pada Gambar 8.

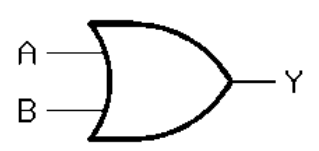

Gambar 8 Simbol gerbang $O R 2$ masukan.

\subsection{Basic4Android}

Basic4android adalah development tool sederhana yang powerful untuk membangun aplikasi Android. Bahasa Basic4android mirip dengan Visual Basic dengan tambahan dukungan untuk objek.

\subsection{DT-AVR Maxiduino}

DT-AVR Maxiduino merupakan modul pengembangan mikrokontroler keluarga AVR Atmega berbasis Atmega 1280 yang kompatibel dengan Arduino ${ }^{\mathrm{TM}} . D T$ AVR Maxiduino dilengkapi dengan program bootloader sehingga tidak membutuhkan divais programmer eksternal. Dengan menggunakan bootloader pada DT-AVR Maxiduino, pengguna dapat menggunakan jalur USB sebagai jalur komunikasi dengan komputer, sekaligus menggunakannya untuk melakukan programming jika ada perbaikan program (update) dengan Arduino $^{\mathrm{TM}}$ IDE. Mikrokontroler DT-AVR Maxiduino membutuhkan power supply saat mendownload program dan tidak kehilangan program yang sudah didownload saat baterai atau power supply dilepas.

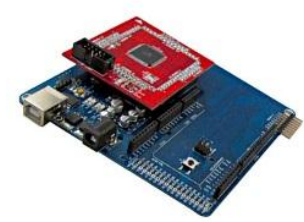

Gambar 9 DT-AVR Maxiduino. 


\subsection{Bluetooth HC-06}

Bluetooth Module HC-06 merupakan module komunikasi nirkabel pada frekuensi $2.4 \mathrm{GHz}$ dengan default koneksi hanya sebagai SLAVE. Sangat mudah digunakan dengan mikrokontroler untuk membuat aplikasi wireless. Interface yang digunakan adalah serial $R X D, T X D, V C C$ dan GND. Built in LED sebagai indikator koneksi bluetooth.

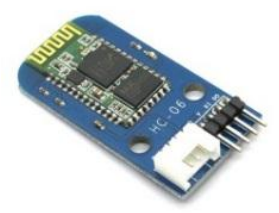

Gambar 10 Bluetooth HC-06.

\section{SIMPULAN}

Puzzle Hijaiyah Elektronik Interaktif sudah berjalan dengan baik hal ini didasari dari hasil pengujian masing-masing sensor. Komunikasi bluetooth antara mikrokontroler dengan smartphone sudah berfungsi dengan baik hal ini di lihat dari data yang dikirim dan diterima telah benar ketika di verifikasi baik itu oleh mikrokontroler maupun pada smartphone.

\section{REFERENSI}

[1] Malvino, Albert., Prinsip-Prinsip Elektronika (Jilid 1), Penerbit Erlangga: Jakarta, 1996.

[2] Gute Mahendra., Puzzle Bukan Sekedar Permainan Anak, diakses pada http://www.bizitstudio.com/detilartikel-102-puzzle-bukan-sekedarpermainan-anak.html tanggal 18 Juni 2013, 2010.

[3] Datasheet DT-AVR Maxiduino Oktober 2013.

[4] http://www.basic4ppc.com/android/forum/threads/how-to-makegames.32593/, diakses pada 2 Maret 2014.

[5] http://thevron.com/anda-juga-bisa-membuat-game-seperti-flappy-birdtanpa-coding/, diakses pada 2 Maret 2014. 
